\title{
3-Amino-1,2,4-Triazole Induces Quick and Strong Fat Loss in Mice with High Fat-Induced Metabolic Syndrome
}

\author{
Valéria Nunes-Souza, ${ }^{1,2,3,4}$ Nelson Miguel Dias-Júnior, ${ }^{1,2}$ \\ Marcos Antônio Eleutério-Silva, ${ }^{1,2,5}$ Vanessa P. Ferreira-Neves, ${ }^{1,2}$ Fabiana Andréa Moura, ${ }^{6}$ \\ Natalia Alenina $(\mathbb{D})^{3,7}$ Michael Bader, ${ }^{3,7,8,9,10}$ and Luíza A. Rabelo $\mathbb{D}^{1,2,3}$ \\ ${ }^{1}$ Laboratório de Reatividade Cardiovascular, Setor de Fisiologia, Instituto de Ciências Biológicas e da Saúde, Universidade Federal \\ de Alagoas, Maceió, Alagoas, Brazil \\ ${ }^{2}$ Núcleo de Síndrome Metabólica, Universidade Federal de Alagoas, Maceió, Alagoas, Brazil \\ ${ }^{3}$ Max-Delbrück-Center for Molecular Medicine, Berlin, Germany \\ ${ }^{4}$ Departamento de Fisiologia e Farmacologia, Centro de Biociências (CB), Universidade Federal de Pernambuco (UFPE), Recife, \\ Pernambuco, Brazil \\ ${ }^{5}$ Faculdade de Medicina, Universidade Federal de Alagoas, Maceió, Alagoas, Brazil \\ ${ }^{6}$ Faculdade de Nutrição (FANUT), Universidade Federal de Alagoas, Maceió, Alagoas, Brazil \\ ${ }^{7}$ German Center for Cardiovascular Research (DZHK), Partner Site Berlin, Germany \\ ${ }^{8}$ Berlin Institute of Health (BIH), Berlin, Germany \\ ${ }^{9}$ Charité University Medicine, Berlin, Germany \\ ${ }^{10}$ Institute for Biology, University of Lübeck, Germany
}

Correspondence should be addressed to Luíza A. Rabelo; luizaa.rabelo@gmail.com

Received 16 August 2019; Revised 22 January 2020; Accepted 24 February 2020; Published 13 April 2020

Academic Editor: Christopher Horst Lillig

Copyright ( 2020 Valéria Nunes-Souza et al. This is an open access article distributed under the Creative Commons Attribution License, which permits unrestricted use, distribution, and reproduction in any medium, provided the original work is properly cited.

\footnotetext{
Background. Obesity is a growing epidemic with limited effective treatments and an important risk factor for several diseases such as metabolic syndrome (MetS). In this study, we aimed to investigate the effect of 3-amino-1,2,4-triazole (ATZ), an inhibitor of catalase and heme synthesis, in a murine model for MetS. Methods. Male C57BL/6 mice with high-fat diet-induced MetS received ATZ $\left(500 \mathrm{mg} \cdot \mathrm{kg}^{-1} \cdot 24 \mathrm{~h}^{-1}\right)$ for 12 weeks. Results. The HFD group showed increased blood pressure and body weight, enhanced fat deposition accompanied by an increase in adipocyte diameter, and decreased lipolysis in white adipose tissue (WAT). The expression of genes related to inflammation was increased in WAT of the HFD group. Concurrently, these mice exhibited an increase in leptin, nonesterified fatty acid (NEFA), insulin, and glucose in plasma, coupled with glucose intolerance and insulin resistance. Strikingly, ATZ prevented the increase in blood pressure and the HFD-induced obesity as observed by lower body weight, WAT index, triglycerides, NEFA, and leptin in plasma. ATZ treatment also prevented the HFD-induced increase in adipocyte diameter and even induced marked atrophy and the accumulation of macrophages in this tissue. ATZ treatment also improved glucose metabolism by increasing glucose tolerance and insulin sensitivity, GLUT4 mRNA expression in WAT in parallel to decreased insulin levels. Conclusions. In the context of HFD-induced obesity and metabolic syndrome, the fat loss induced by ATZ is probably due to heme synthesis inhibition, which blocks adipogenesis by probably decreased $\operatorname{RevErb} \alpha$ activity, leading to apoptosis of adipocytes and the recruitment of macrophages. As a consequence of fat loss, ATZ elicits a beneficial systemic antiobesity effect and improves the metabolic status.
} 


\section{Introduction}

Obesity is a growing epidemic with limited effective treatments and an important risk factor for several diseases such as the metabolic syndrome (MetS). This condition is characterized by a group of symptoms [1], including obesity, hypertension, hypertriglyceridemia, dyslipidemia, glucose intolerance, and insulin resistance $[1,2]$. White adipose tissue (WAT), the primary lipid storage depot [3], is central to the development of the MetS, while being a powerful endocrine organ [4]. Increased fat accumulation is closely related to cardiometabolic diseases, and thereby, the control of fat deposition becomes pivotal to maintain a healthy life [3]. Currently, one of the most discussed theories that attempts to explain the pathological conditions associated with MetS involves the participation of oxidative stress, resulting from changes in redox state, with a predominance of prooxidant systems over antioxidants [5].

3-Amino-1,2,4-triazole (ATZ) is a heterocyclic organic compound widely used as a catalase inhibitor [6], a ubiquitous enzyme which metabolizes $\mathrm{H}_{2} \mathrm{O}_{2}$ to oxygen and water. Probably linked to its main function, this compound also inhibits $\alpha$-oxidation [7], fatty acid synthesis, and lipogenesis in isolated hepatocytes. In human differentiated adipocytes, ATZ treatment impaired the antioxidant defense system and induced inflammation [8]. Park et al. [9] have demonstrated that the pharmacological or genetic inhibition of catalase alters macrophage activation and thereby induces inflammation of adipose tissue, suggesting a novel role of endogenous catalase in macrophage polarization in adipose tissue. In animals, the median lethal dose $\left(\mathrm{LD}_{50}\right)$, which ensures low acute toxicity [10]. However, the doses vary according to some species already studied: in mice, the $\mathrm{LD}_{50}$ was $11,000 \mathrm{mg} \cdot \mathrm{kg}^{-1}$; in sheep, $4,000 \mathrm{mg} \cdot \mathrm{kg}^{-1}$ was fatal; in rats, no signs of toxicity with $4,080 \mathrm{mg} \cdot \mathrm{kg}^{-1}$ were observed [11]; in bacterial and cultured mammalian cells and rodents exposed in vivo, the ATZ was not genotoxic [12]. Steinhoff and coauthors did not observe carcinogenic activity of ATZ in golden hamsters or in mice fed with ATZ in a lifespan test at dietary levels of 1,10 , and $100 \mathrm{ppm}$ ( $\mathrm{rg}$ amitrole $\cdot \mathrm{g}^{-1}$ food), until they died spontaneously. However, in rats, thyroid and pituitary gland tumors were detected, induced by ATZ [13].

ATZ also inhibits aminolevulinic acid dehydratase, a key enzyme in heme synthesis. Heme activates the transcription repressor $\operatorname{RevErb} \alpha$, which is essential for adipocyte differentiation [14]. Thus, ATZ may inhibit adipogenesis by blocking the synthesis of heme. It has been shown that ATZ induces fat loss and decreases plasma triacylglycerol levels in mice [15]. However, the relevance of this phenomenon in MetS, as well as the mechanism by which ATZ induces fat loss, still remain unclear. We have inquired if ATZ decreases lipid storage by increasing inflammation and cell death, by decreasing adipogenesis, and/or by lipolysis. To address these questions, we used high-fat diet- (HFD-) induced MetS in mice, a widely used model to test pharmacological effects on obesity [16].

\section{Methods}

2.1. Ethics Statement and Animal Care. All experiments reported here have been conducted in accordance with the National Institutes of Health Guide for the Care and Use of Laboratory Animals (Institute of Laboratory Animal Resources, National Academy Press, Washington, DC, 1996). The procedures were approved by the Ethical Committee of the Federal University of Alagoas (029/2014). All the animals were housed in an animal facility on a 12-hour light/dark cycle, and food and water were available ad libitum.

2.2. Diets and Research Design. C57BL/6 male mice (4-6 weeks old) were randomly divided into three groups: a control (CT, $n=7$ ), which was fed with standard diet (caloric intake $=11.8 \%$ fat), the second group was fed with HFD (caloric intake $=58.4 \%$ fat, primarily lard) $(\mathrm{HFD}, n=$ 6 ), and the third group was fed with HFD treated by dietary supplementation with ATZ (HFD+ATZ, $n=8 ; 500 \mathrm{mg} \cdot \mathrm{kg}^{-1}$ $24 \mathrm{~h}^{-1}$ ). The HFD was prepared according to Nunes-Souza et al. [16], and all components were purchased from Rhoster ${ }^{\circledR}$ LTDA (São Paulo, Brazil) and Sigma ${ }^{\circledR}$ (Seelze, Germany). The animals were evaluated during 20 weeks in total. However, the treatment with ATZ (Sigma ${ }^{\circledR}$, Seelze, Germany) started at the beginning of the eighth week of HFD feeding. The dose and mode of application of ATZ administration were determined in a pilot experiment, which indicated that $500 \mathrm{mg} \cdot \mathrm{kg}^{-1}$ of ATZ promotes lipolytic effect and reduction of visceral adiposity (unpublished data). The dose of ATZ was adjusted weekly, taking into account the mean body weight and the food intake, which were assessed weekly in a semianalytical scale.

\subsection{In Vivo and In Vitro Experiments}

2.3.1. Systolic Blood Pressure and Metabolic Assessments. At the end of the treatment, the animals were adapted to a small mouse holder during one week. The measurement of systolic blood pressure was recorded by tail plethysmography

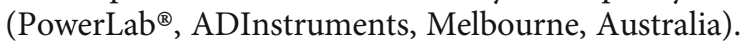

Intraperitoneal (i.p) glucose tolerance test (GTT) was carried out in overnight-fasted mice (12 hours), and insulin tolerance test (ITT) was performed in overnight fed; both were conducted accordingly as described previously [16]. The product of fasting triglyceride and glucose levels (TyG index), a validated and highly sensitive marker of insulin resistance, was calculated using the following formula $[17,18]$ : TyG index $=$ Ln [triglyceride $\left(\mathrm{mg} \cdot \mathrm{dL}^{-1}\right) \times$ glucose $\left(\mathrm{mg} \cdot \mathrm{dL}^{-1}\right) / 2$ ]

\subsubsection{Lipolysis}

(1) In Vivo. In an independent group of animals in fed conditions, the lipolysis in vivo was performed by administration of $1 \mathrm{mg} \cdot \mathrm{kg}^{-1}$, i.p selective adrenergic $\beta 3$-receptor agonist, the CL-316,243 hydrate (C5976; Sigma-Aldrich ${ }^{\circledR}$, Seelze, Germany) $[19,20]$. The blood was collected from tail vein before the administration and after, in 15 and 30 minutes. Nonesterified fatty acid (NEFA) was measured in plasma and normalized by the white adipose tissue (WAT) index, which was obtained after euthanasia.

(2) In Vitro. To determine the influence of ATZ $(50 \mathrm{mmmol}$ $\left.\cdot \mathrm{L}^{-1}\right)$, catalase $\left(1,200 \mathrm{~mL}^{-1}\right)$, and $\mathrm{H}_{2} \mathrm{O}_{2}\left(0.1 \mathrm{mmmol} \cdot \mathrm{L}^{-1}\right)$ separately, we performed the lipolysis in vitro in WAT collected 
from $\mathrm{C} 57 \mathrm{Bl} / 6$ mice feeding chow diet. The tissue was incubated in a medium of culture (DMEM, Gibco ${ }^{\circledR} 11880$; Darmstadt, Germany) in a bath $\left(37^{\circ} \mathrm{C} ; 95 \% \mathrm{O}_{2} ; 5 \% \mathrm{CO}_{2}\right)$ for 30 minutes for collection of basal time (time 0 ). Immediately after that, the medium was imbibed with CL-316,243 0.1 mM alone and in combination with ATZ, CAT, and $\mathrm{H}_{2} \mathrm{O}_{2}$ separately. The NEFA were measured in the medium in 0,90 , and 180 minutes of incubation and normalized by the amount of fat used for stimulation.

2.4. Euthanasia and Ex Vivo Experiments. In fasted state, all animals were anesthetized $\left(100 \mathrm{mg} \cdot \mathrm{kg}^{-1}\right.$ ketamine, $10 \mathrm{mg} \cdot \mathrm{kg}^{-}$ ${ }^{1}$ xylazine, i.p). In the sequence, animals were euthanized by exsanguination through the right ventricle puncture. Plasma was obtained after blood centrifugation $(2,150 \mathrm{~g})$ at $4^{\circ} \mathrm{C}$ for 10 minutes. The epididymal and perirenal WAT, as well as interscapular brown adipose tissue (BAT), were removed, weighed, and stored at $-80^{\circ} \mathrm{C}$ until further analysis. WAT index was calculated using the following formula: WAT index $(\%)=\left[\left(\right.\right.$ epididymal fat $_{(\mathrm{g})}+$ perirenal fat $\left._{(\mathrm{g})}\right) /\left(\right.$ body weight $\left._{(\mathrm{g})}\right)$ * 100]. The relative weight (\%) of tissue was calculated using the following formula: relative weight $(\%)=\left[\right.$ tissue $_{(\mathrm{g})} /$ body weight $\left.\left._{(\mathrm{g})}\right) * 100\right]$. The right tibias were removed, and the length was measured using a pachymeter.

2.4.1. Circulating Biochemical Analysis. Fasting total cholesterol (TCOL), triglycerides (TG) (Labtest ${ }^{\circledR}$, Lagoa Santa, Brazil), and NEFA (Wako Chemicals $\mathrm{GmbH}^{\circledR}$, Germany) levels in plasma were assayed using commercial kits following the manufacturers' instructions and performed in a microplate (Thermo Scientific ${ }^{\circledR}$, Software 2.4 Multiskan Spectrum, Finland). ELISA assays were used to measure insulin and leptin levels (Millipore ${ }^{\circledR}$, Schwalbach, Germany) according to the manufacturers' instructions.

2.4.2. Evaluation of eWAT Redox Status. A piece of frozen eWAT was homogenized in a RIPA lysis buffer ( $\mathrm{pH}$ 7.5; Cell Signaling Technology ${ }^{\circledR}$, Beverly, MA) containing protease and phosphatase inhibitor cocktails (Roche ${ }^{\circledR}$, Mannheim, Germany). Total protein levels were determined by the Bradford assay [21]. The eWAT catalase activity was measured according to $\mathrm{Xu}$ and colleagues [22], and enzyme activity was expressed in $\mu \mathrm{mol} \cdot \mathrm{min} \cdot \mathrm{mL}^{-1}$ per eWAT protein $\left(\mathrm{mg} \cdot \mathrm{mL}^{-1}\right)$ [21]. Total superoxide dismutase (SOD) activity was assessed with a commercial colorimetric kit (\#19160, Sigma ${ }^{\circledR}$, Seelze, Germany) following the manufacturer's instructions. Lipid peroxidation in eWAT was determined by measuring the thiobarbituric acid reactive substances (TBARS), as a marker of oxidative stress, mainly malondialdehyde (MDA). The quantification was performed according to Ohkawa et al. [23] with modifications, as previously described [24]. Data were normalized per total protein concentration, measured by Bradford [21] and expressed as $\mathrm{nM} \cdot \mathrm{mg}$ protein $^{-1}$.

Hydrogen peroxide $\left(\mathrm{H}_{2} \mathrm{O}_{2}\right)$ was measured by fluorescence using the Amplex ${ }^{\circledR}$ UltraRed hydrogen peroxide (10-acetyl-3,7-dihydroxiphenoxazine) assay (Invitrogen ${ }^{\circledR}$, Paisley, United Kingdom) as described [24].
2.4.3. Gene Expression in Epididymal White Adipose Tissue. Gene expression was determined by real-time quantitative polymerase chain reaction (qPCR). Briefly, total RNA was isolated from epididymal white adipose tissue (eWAT) by using trizol (TRizol ${ }^{\circledR}$ Reagent, Darmstadt, Germany), quantified by spectrophotometry, and $1 \mu \mathrm{g}$ was used for the synthesis of cDNA by reverse transcriptase (Invitrogen ${ }^{\circledR}$ ). Subsequently, the product was amplified using the GoTaq qPCR Master Mix (Promega ${ }^{\circledR}$; Mannheim, Germany) by real-time quantitative PCR (ABI 7900HT Real-Time PCR System-Applied Biosystems ${ }^{\circledR}$, Darmstadt, Germany). mRNA was quantified as a relative value compared with an internal reference, GAPDH. Quantitative values for mRNA expression were obtained by the parameter $2^{-\Delta \Delta \mathrm{Ct}}$ method [25]. The primers used for real-time quantitative PCR are listed in Table 1.

2.4.4. Histological Analysis in eWAT. Small fragments of eWAT was fixed in $4 \%$ buffered formaldehyde, embedded in paraffin, and sectioned at $10 \mu \mathrm{m}$. H\&E images were used for the determination of mean adipocyte size and macrophage count. The sections were observed under an Olympus BX51 attached DP70 Digital Camera System (Tokyo, Japan); the fields were evaluated with final magnification of $20 \mathrm{x}$ $(50 \mu \mathrm{m})$. Digital photographs were taken from each section, adipocyte size expression were quantified using the "ImageJ" image processing software (NIH, Bethesda, MD, USA), and the macrophage count was performed on the average of 4 fields per animal (macrophage/field) [26-28].

2.5. Data Analysis. Results are expressed as mean \pm SEM, and " $n$ " indicates the number of animals used in the experiment. The dose-response curves of the different groups were compared by two-way ANOVA followed by Bonferroni's correction. One-way ANOVA was used for other comparisons followed by Bonferroni tests using GraphPad Prism ${ }^{\circledR}$ version 5.0 for Windows. A value of $p<0.05$ was considered significant.

\section{Results}

3.1. ATZ Decreases Body Weight, WAT Depots, Lipid Profile, and Blood Pressure in High Fat-Induced MetS Mice. MetS was induced in mice by HFD for 20 weeks. At week 8, one group was additionally treated with $500 \mathrm{mg} \cdot \mathrm{kg}^{-1} 24 \mathrm{~h}^{-1}$ of ATZ. The HFD group showed a significant increase in body weight from the third until the $20^{\text {th }}$ week of HFD consumption compared to the control (Figure 1(a)). Strikingly, after one week of ATZ treatment until the end of the experimental protocol (from the $9^{\text {th }}$ week until $20^{\text {th }}$ week), the body weight decreased significantly compared to the HFD group (Figure 1(a) and Table 2). The data demonstrate the effect of HFD on body weight gain, as well as the effect of ATZ on weight loss. Due to the higher caloric and lipid content of HFD, food intake was reduced in both groups fed a HFD irrespective of ATZ treatment. Tibia length and total plasma protein were similar between the groups (Table 2).

After HFD consumption, the systolic blood pressure, WAT index, and epididymal and perirenal adipose tissue 
TAble 1: Primer sequences used for real-time quantitative PCR (amplicons between 100 and $150 \mathrm{bp}$ ).

\begin{tabular}{|c|c|}
\hline Primers & Sequence forward and reverse $\left(5^{\prime}-3^{\prime}\right)$ \\
\hline \multirow{2}{*}{ Adiponectin } & F: GGAACTTGTGCAGGTTGGAT \\
\hline & R: CCTTCAGCTCCTGTCATTCC \\
\hline \multirow{2}{*}{$\operatorname{Adr} \beta 3$} & F: GCTGACTTGGTAGTGGGACTC \\
\hline & R: TAGAAGGAGACGGAGGAGGAG \\
\hline \multirow{2}{*}{ Caspase 1} & F: ACCCTCAAGTTTTGCCCTTT \\
\hline & R: GATCCTCCAGCAGCAACTTC \\
\hline \multirow{2}{*}{ Catalase } & F: CACGCTGGTAGTTGGCCACT \\
\hline & R: GCCCAGCCCTGACAAAATGC \\
\hline \multirow{2}{*}{ CCL2 } & F: GCCAACTCTCACTGAAGCC \\
\hline & R: GCTGGTGAATGAGTAGCAGC \\
\hline \multirow{2}{*}{ CD68 } & F: TAGGACCGCTTATAGCCCAAG \\
\hline & R: CTGTAGGTGTCATCGTGAAG \\
\hline \multirow{2}{*}{ CIDEA } & F: GCAGCCTGCAGGAACTTATC \\
\hline & R: CCGATTTCTTTGGTTGCTTG \\
\hline \multirow{2}{*}{ GAPDH } & F: CCATCACCATCTTCCAGGAG \\
\hline & R: GTGGTTCACACCCATCACAA \\
\hline \multirow{2}{*}{ GLUT4 } & F: TGATTCTGCTGCCCTTCTGT \\
\hline & R: GGACATTGGACGCTCTCTCT \\
\hline \multirow{2}{*}{ HSL } & F: ACGGATACCGTAGTTTGGTGC \\
\hline & R: TCCAGAAGTGCACATCCAGGT \\
\hline \multirow{2}{*}{ IR } & F: CCACCAATACGTCATTCACAAC \\
\hline & R: GGGCAGATGTCACAGAATCAA \\
\hline \multirow{2}{*}{ Interleukin- $1 \beta$} & F: GCCACCTTTTGACAGTGATGAG \\
\hline & R: CCTGAAGCTCTTGTTGATGTGC \\
\hline \multirow{2}{*}{ Interleukin 18} & F: TCTGACATGGCAGCCATTGT \\
\hline & R: CAGGCCTGACATCTTCTGCAA \\
\hline \multirow{2}{*}{ Lep } & F: CGTGTGTGAAATGTCATTGATCCT \\
\hline & R: GACACCAAAACCCTCATCAAGAC \\
\hline \multirow{2}{*}{ LPL } & F: AGTGGCCGAGAGCGAGAAC \\
\hline & R: CCACCTCCGTGTAAATCAAGAAG \\
\hline \multirow{2}{*}{$\operatorname{PPAR} \gamma$} & F: TCAGCTCTGTGGACCTCTCC \\
\hline & R: ACCCTTGCATCCTTCACAAG \\
\hline \multirow{2}{*}{$\operatorname{RevErb} \alpha$} & F: TGGCCTCAGGCTTCCACTATG \\
\hline & R: CCGTTGCTTCTCTCTCTTGGG \\
\hline \multirow{2}{*}{ SOD1 } & F: GACGGTGTGGCCAATGTGTC \\
\hline & R: CAAGCGGCTCCCAGCATTTC \\
\hline \multirow{2}{*}{ TNF- $\alpha$} & F: GTCTACTGAACTTCGGGGTGA \\
\hline & R: CTCCTCCACTTGGTGGTTTG \\
\hline \multirow{2}{*}{ UCP2 } & F: GCATTGGCCTCTACGACTCT \\
\hline & R: GTCCTGGTATCTCCGACCAC \\
\hline
\end{tabular}

$\operatorname{Adr} \beta 3$ : adrenergic $\beta 3$ receptor; CCL2 or MCP1: monocyte chemoattractant protein 1; CD68: cluster of differentiation 68; CIDEA: cell death activator; GAPDH: glyceraldehyde 3-phosphate dehydrogenase; GLUT4: glucose transporter type 4; HSL: hormone-sensitive lipase; IR: insulin receptor; Lep: leptin; LPL: lipoprotein lipase; PPAR $\gamma$ : peroxisome proliferator-activated receptor gamma; RevErb $\alpha$ or NR1D1: nuclear receptor subfamily 1; SOD1: superoxide dismutase 1; TNF- $\alpha$ : tumor necrosis factor alpha; UCP2: uncoupling protein 2 . increased significantly compared to the control (CT) group. However, after ATZ treatment, all of these parameters were significantly reduced (Figure 1(b) and Table 2). On the other hand, brown adipose tissue significantly increased only in the HFD+ATZ group (Table 2), suggesting a probable action of ATZ treatment in adipocyte differentiation and thermogenesis.

The expression of mRNA for adiponectin in WAT was significantly decreased in both, the HFD and HFD+ATZ groups compared to CT (Figure 1(c)). Consistently with the increased amount of visceral WAT and an unchanged mRNA level (Figure 1(d)), the plasma levels of leptin were significantly higher in HFD animals (Figure 1(e)). Interestingly, in HFD+ATZ mice, both protein and gene expressions of leptin were significantly lower compared to the HFD group (Figures 1(d) and 1(e), respectively).

The fasting plasmatic levels of TCOL and nonesterified fatty acid (NEFA) were significantly increased in the HFD group compared to $\mathrm{CT}$, with no changes in TG levels (Table 2). Concurrent with the decrease in fat depots, the levels of TG and NEFA, but not TCOL, were also significantly decreased in the HFD+ATZ group (Table 2).

The lipolytic activity of WAT was measured in vivo by stimulation with CL-316,243 hydrate, a selective $\beta 3$-adrenoceptor agonist. The release of NEFA was significantly lower over time (15 and 30 minutes after stimulation) in the HFD group compared to the CT group (Figure 2(a)). In contrast, NEFA release was significantly higher before and 15 and 30 minutes after stimulation in the HFD+ATZ group than in the HFD group and indistinguishable from controls, which could explain the lower fat depot in these animals. The data demonstrate the decrease in lipolysis induced by HFD, as well as the increase in this parameter induced by ATZ. The basal NEFA at time point 0 was different among the three groups because it was normalized by the WAT index $\left(\mathrm{mmol} / \mathrm{L} \cdot \mathrm{WAT}\right.$ index $\left.{ }^{-1}\right)$, which is different among groups.

In order to determine the influence of ATZ, catalase, and $\mathrm{H}_{2} \mathrm{O}_{2}$ separately, the same lipolysis assay was performed in vitro in eWAT. The results showed no significant difference at baseline and after 90 and 180 minutes of stimulation between the groups that received only CL-316,243 hydrate or associated with ATZ, catalase, or $\mathrm{H}_{2} \mathrm{O}_{2}$ (Figure 2(b)), suggesting that the elevated lipolysis induced by ATZ in vivo does not involve the direct action of these substances on the breakdown of triglycerides within adipocytes.

Analysis of the expression of genes involved in lipolysis showed that HFD induced a significant decrease in adrenergic $\beta 3$-receptor ( $\beta 3$ ), lipoprotein lipase (LPL), and hormonesensitive lipase (HSL) mRNA in WAT (Figures 2(c)-2(e)). ATZ treatment decreased even further the levels of $\beta 3$ mRNA but did not change LPL mRNA expression compared to the HFD group (Figures 2(c) and 2(d)). However, HSL mRNA expression was significantly higher in the HFD+ATZ animals than in the HFD group (Figure 2(e)), which could explain the increased lipolysis induced by ATZ in vivo, since HSL is a lipolytic enzyme responsible for the breakdown of triglycerides stored in adipocytes to free fatty acids.

Histological analysis of eWAT showed a significant increase in the adipocyte diameter after HFD consumption, 


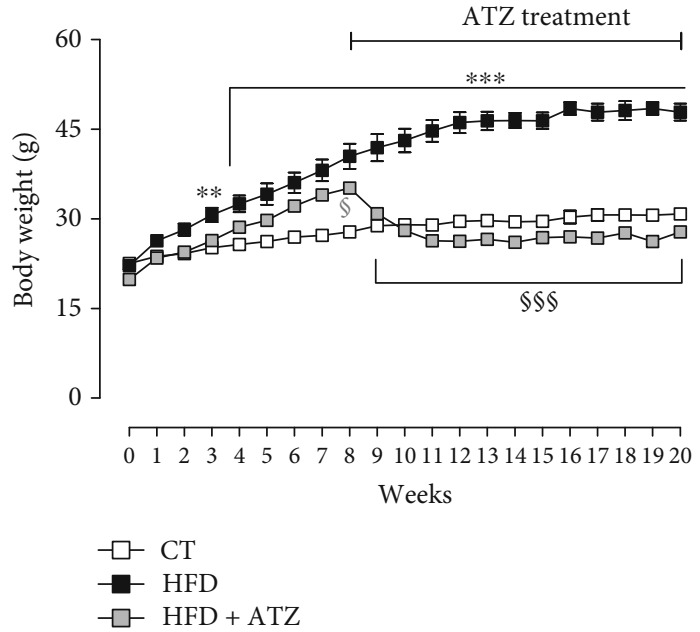

(a)

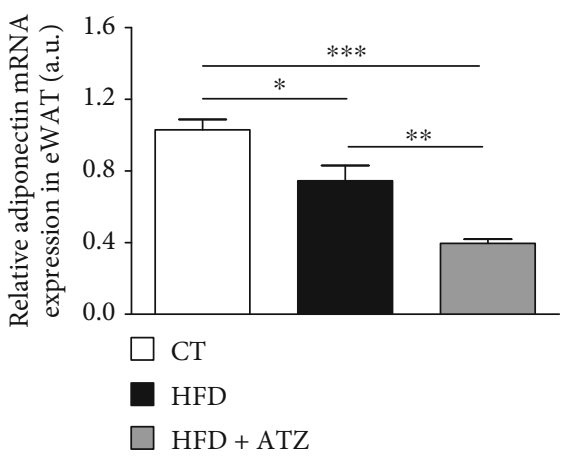

(c)

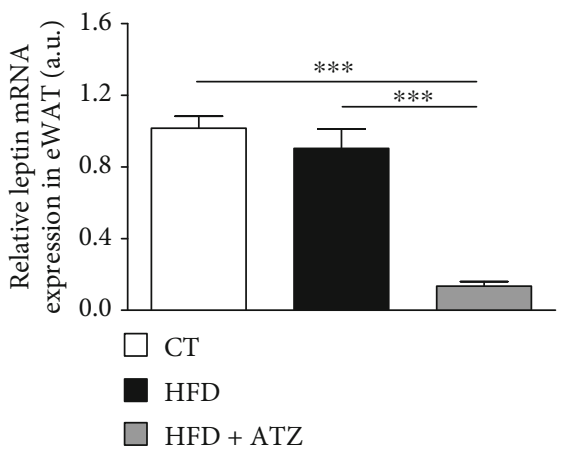

(d)

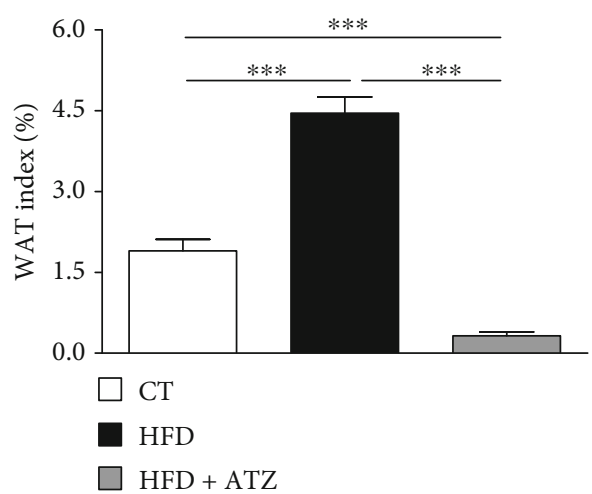

(b)

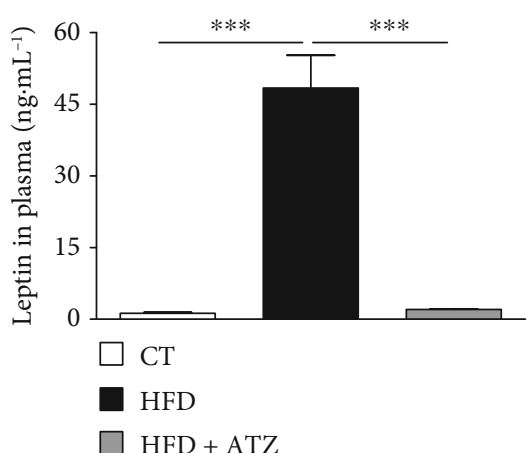

(e)

Figure 1: (a) Body weight during the weeks of treatment (g); (b) WAT index (\%); (c, d) relative gene expression of adiponectin and leptin, respectively, in epididymal white adipose tissue (eWAT) (arbitrary units); (e) leptin levels in plasma (ng.mL ${ }^{-1}$ ) of C57BL/6 mice after dietetic intervention (chow and high-fat) and oral treatment with ATZ $\left(500 \mathrm{mg} \cdot \mathrm{kg}^{-1}\right)$. Each point on the graph represents the mean \pm SEM. ANOVA (two-way): ${ }^{* *} p<0.001 ;{ }^{* * *} p<0.001$ HFD vs. CT; ${ }^{\circledR} p<0.05 ;{ }^{\varsigma s \S} p<0.001$ HFD+ATZ $v s$. HFD. Each bar graph represents the mean \pm SEM. ANOVA (one-way): ${ }^{*} p<0.05,{ }^{* *} p<0.01$, and ${ }^{* * *} p<0.001$.

indicating large accumulation of triglycerides. ATZ prevented this effect and even induced marked atrophy and an accumulation of macrophages in this tissue (Figures 3(a)$3(\mathrm{e}))$.

3.2. ATZ Modulates Markers of Inflammation, Cell Death, Adipogenesis, and Oxidative Status in eWAT. We next hypothesized that the marked atrophy in eWAT after ATZ treatment could be due to the activation of pathways involved in inflammation, cell death, inhibition of adipogenesis, and/or high oxidative stress. Related to the inflammatory pathway, the gene expression of cluster of differentiation 68 (CD68), monocyte chemoattractant protein 1 (MCP1 or CCL2), and interleukin-1 $\beta$ (IL-1 $\beta$ ) was significantly increased in the HFD group compared to the CT group, and the ATZ treatment increased it even more (Figures 4(a), 4(b), and 4(e), respectively). The amount of mRNA for caspase 1, tumor necrosis factor alpha (TNF- $\alpha$ ), and IL-18 was not different between CT and HFD, but ATZ treatment significantly increased their levels compared to HFD (Figures 4(c), 4(d), and 4(f), respectively). The mRNA for CIDEA, a cell death marker, and also for PPAR $\gamma$ (peroxisome proliferatoractivated receptor gamma) and $\operatorname{RevErb} \alpha$, both involved in adipogenesis, were significantly decreased in the HFD compared to the CT group. However, in the ATZ group, the expression of these genes increased significantly compared to the HFD group (Figures $4(\mathrm{~g})-4(\mathrm{i})$, respectively).

In the evaluation of the redox profile, mRNA for SOD1 (the $\mathrm{Cu}-\mathrm{Zn}$-cytoplasmic isoform) and catalase were significantly decreased in the HFD compared to the CT group (Figures 5(a) and 5(b)). However, the gene expression of mitochondrial uncoupling protein 2 (UCP2), an anion carrier protein, showed no significant differences between the HFD group and the CT group (Figure 5(c)). ATZ treatment significantly further decreased SOD expression in eWAT. Interestingly, catalase and UCP2 mRNA expression were increased even compared to the control group (Figures 5(b) and 5(c)). Despite changes in its mRNA, total SOD activity in eWAT was not different between the groups (Figure 5(d)). Catalase activity was slightly decreased after ATZ treatment despite upregulation of its mRNA (Figure 5(e)). Lipid peroxidation, measured by TBARS levels in eWAT, was decreased 
TABLE 2: General characteristics from control, HFD, and HFD+ATZ (500 mg.kg $\left.{ }^{-1}\right)$ treated mice.

\begin{tabular}{|c|c|c|c|}
\hline \multirow{2}{*}{ Parameter } & \multicolumn{3}{|c|}{ Groups } \\
\hline & $\mathrm{CT}$ & HFD & HFD+ATZ \\
\hline Final systemic fasting glucose & $103.3 \pm 7.1$ & $180.2 \pm 13.86^{\mathrm{a}}$ & $154.5 \pm 5.65^{\mathrm{c}}$ \\
\hline Food intake (g/body weight.day $\left.{ }^{-1}\right)$ & $0.16 \pm 0.00$ & $0.081 \pm 0.00^{\mathrm{a}}$ & $0.08 \pm 0.00$ \\
\hline Final body weight (g) & $32.19 \pm 0.27$ & $47.87 \pm 1.41^{\mathrm{a}}$ & $27.83 \pm 0.20^{\mathrm{b}, \mathrm{c}}$ \\
\hline$\Delta$ body weight (final minus basal) & $10.95 \pm 0.51$ & $25.69 \pm 0.89^{\mathrm{a}}$ & $7.99 \pm 0.59^{\mathrm{b}, \mathrm{c}}$ \\
\hline$\Delta$ body weight (g) (final minus start of ATZ treatment) & $3.78 \pm 0.63$ & $7.40 \pm 0.77^{\mathrm{a}}$ & $-7.31 \pm 0.90^{\mathrm{b}, \mathrm{c}}$ \\
\hline Systolic blood pressure & $118.0 \pm 2.44$ & $134.8 \pm 5.16^{\mathrm{a}}$ & $118.9 \pm 3.27^{\mathrm{b}}$ \\
\hline Epididymal adipose tissue (\%) & $1.36 \pm 0.13$ & $3.05 \pm 0.19^{\mathrm{a}}$ & $0.26 \pm 0.06^{\mathrm{b}, \mathrm{c}}$ \\
\hline Perirenal adipose tissue (\%) & $0.67 \pm 0.18$ & $1.67 \pm 0.22^{\mathrm{a}}$ & $0.08 \pm 0.02^{\mathrm{b}, \mathrm{c}}$ \\
\hline Brown adipose tissue $(\%)$ & $0.32 \pm 0.03$ & $0.33 \pm 0.01$ & $0.84 \pm 0.04^{\mathrm{b}, \mathrm{c}}$ \\
\hline Total cholesterol $\left(\mathrm{mg} \cdot \mathrm{dL}^{-1}\right)$ & $85.78 \pm 2.84$ & $135.6 \pm 10.59^{\mathrm{a}}$ & $110.3 \pm 20.26$ \\
\hline Triglycerides $\left(\mathrm{mg} \cdot \mathrm{dL}^{-1}\right)$ & $57.70 \pm 8.6$ & $83.98 \pm 15.04$ & $41.51 \pm 8.7^{\mathrm{b}}$ \\
\hline Nonesterified fatty acid $\left(\mathrm{NEFA}-\mathrm{mmol} \cdot \mathrm{L}^{-1}\right)$ & $0.38 \pm 0.04$ & $0.60 \pm 0.05^{\mathrm{a}}$ & $0.17 \pm 0.0^{\mathrm{b}, \mathrm{c}}$ \\
\hline Right tibia (mm) & $18.1 \pm 0.01$ & $17.8 \pm 0.03$ & $18.4 \pm 0.02$ \\
\hline Total plasma proteins $\left(\mathrm{mg} \cdot \mathrm{mL}^{-1}\right)$ & $7.96 \pm 0.07$ & $8.13 \pm 0.14$ & $8.01 \pm 0.05$ \\
\hline
\end{tabular}

Values represent the mean \pm SEM. ANOVA one-way: ${ }^{a} p<0.05$ HFD vs. CT. ${ }^{b} p<0.05$ HFD+ATZ vs. HFD. ${ }^{c} p<0.05$ HFD+ATZ vs. CT.

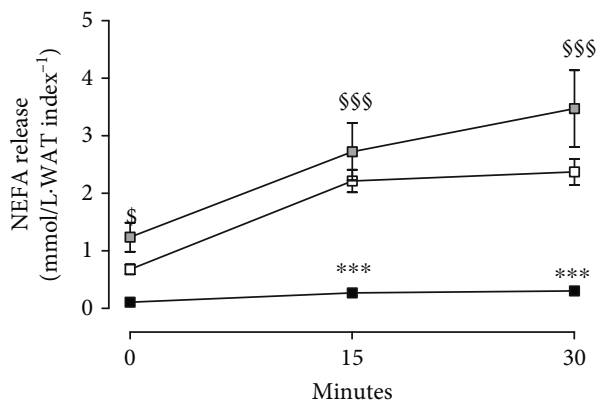

$$
\begin{aligned}
& \square \text { CT } \\
& \square \text { HFD } \\
& \rightarrow-\text { HFD + ATZ }
\end{aligned}
$$

(a)

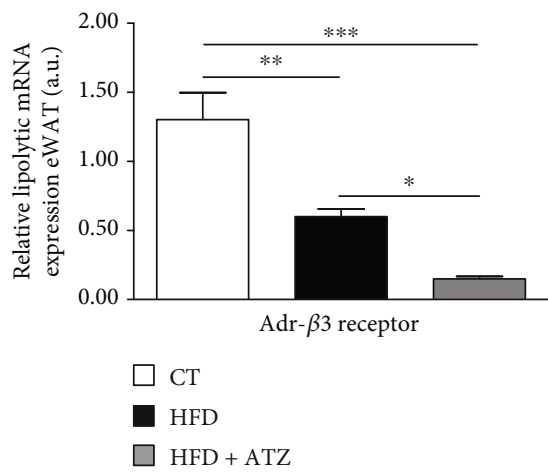

(c)

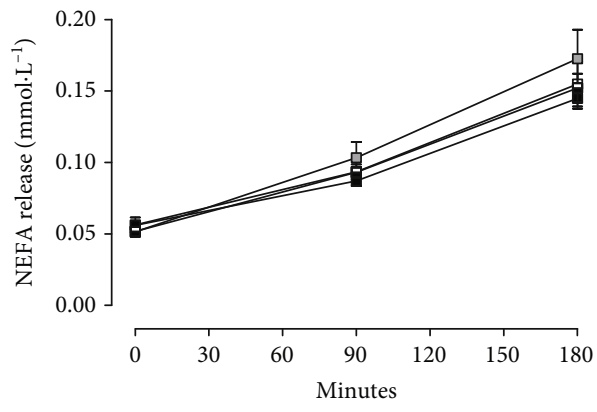

$\square-$ Control $\quad \square-$ ATZ

$\mathrm{H}_{2} \mathrm{O}_{2} \rightarrow \mathrm{CAT}$

(b)

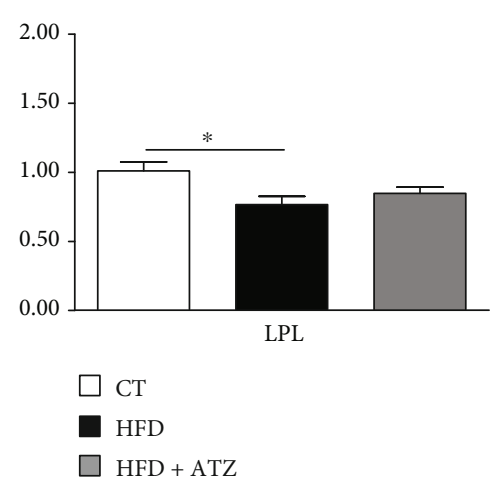

(d)

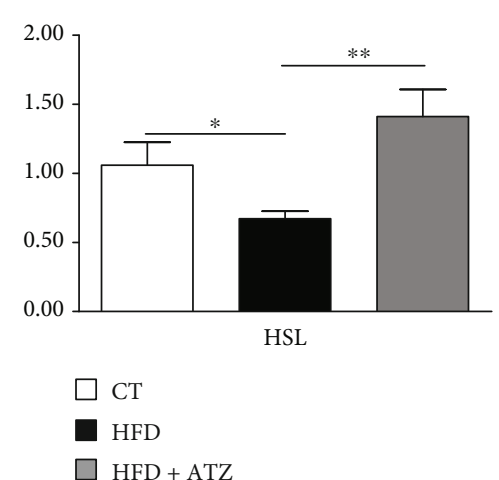

(e)

Figure 2: (a, b) NEFA release after lipolysis in vivo $\left(\mathrm{mmol}^{-1} \mathrm{~L}^{-1}\right.$ WAT index ${ }^{-1}$ ) and in vitro (mmol.L $\mathrm{L}^{-1}$ ), respectively; (c-e) relative gene expression of Adr $\beta 3$, LPL, and HSL in eWAT (arbitrary units, respectively) of C57BL/6 mice after dietetic intervention (chow and highfat) and oral treatment with ATZ $\left(500 \mathrm{mg} \cdot \mathrm{kg}^{-1}\right)$. Each point on the graph represents the mean \pm SEM. ANOVA (two-way): ${ }^{* * *} p<0.001$ HFD vs. CT; ${ }^{\circledR} p<0.05 ;{ }^{\$ S \S} p<0.001$ HFD+ATZ vs. HFD. Each bar graph represents the mean \pm SEM. ANOVA (one-way): ${ }^{*} p<0.05,{ }^{* *} p<$ 0.01 , and ${ }^{* * *} p<0.001$. 


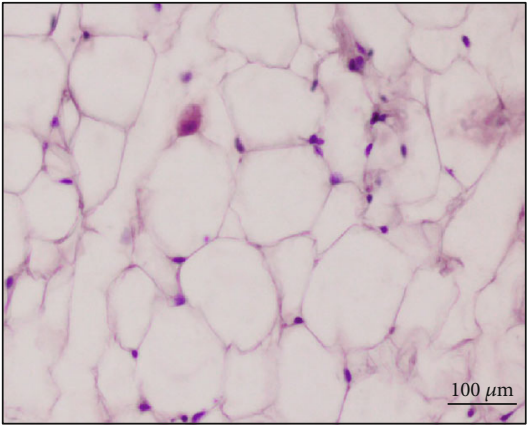

(a)

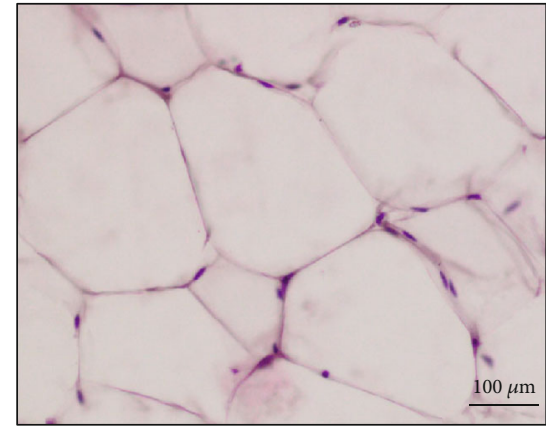

(b)

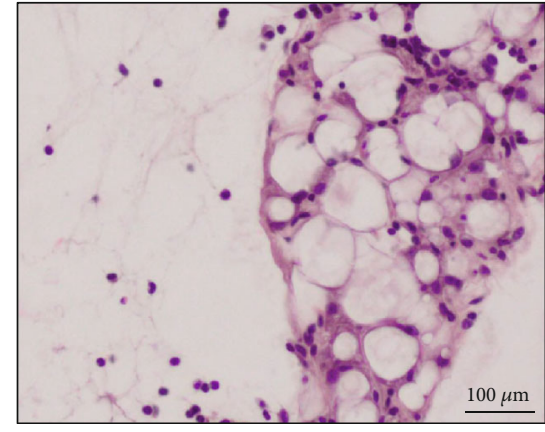

(c)

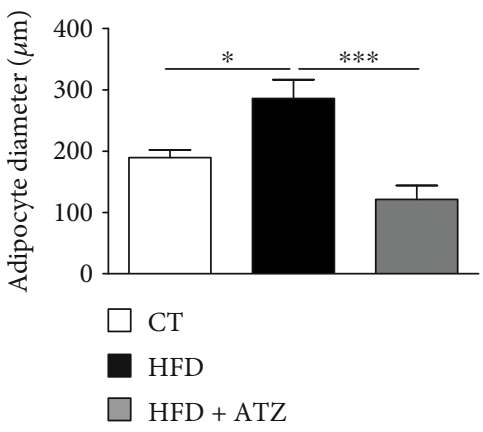

(d)

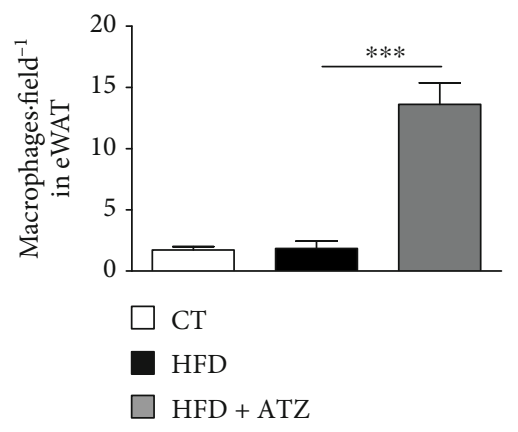

(e)

FIGURE 3: Photomicrographs of a section of the epididymal adipose tissue show the adipocytes after staining with hematoxylin-eosin (HE; (a) CT, (b) HFD, and (c) HFD+ATZ); (b) adipocyte with triglyceride accumulation confirmed by the larger diameter of the cell ( $v$ s. CT group); (c) several nuclei probably of infiltrating macrophages; (d) white adipocyte diameter $(\mu \mathrm{m})$ in eWAT; (e) macrophage/field in WAT. Each bar graph represents the mean \pm SEM. ANOVA (one-way): ${ }^{*} p<0.05 ;{ }^{* * *} p<0.001$.

by ATZ treatment in the HFD groups (Figure 5(f)). On the other hand, the levels of $\mathrm{H}_{2} \mathrm{O}_{2}$ in eWAT were equally decreased in the HFD and HFD+ATZ groups compared to the CT group (Figure 5(g)).

\subsection{ATZ Ameliorates High-Fat Diet-Induced Impairment in} Glucose Metabolism. Fasting blood glucose was clearly increased in both groups fed with HFD (Table 2). Glucose tolerance was impaired after HFD consumption but not when the animals were treated with ATZ (Figure 6(a)); this is observed by the significant increase in the glycemic curve over time in the HFD group compared to the CT group, as well as the significant decrease in the same curve in the HFD+ATZ group compared to the HFD group, evidencing the opposite effect of HFD and ATZ on glucose tolerance. The mRNA for GLUT4 in eWAT was significantly decreased in the HFD group compared to the CT group, and ATZ attenuated this effect (Figure 6(b)). Accordingly, the increase in insulin resistance observed by the significant increase in the glycemic curve over time in HFD animals was also attenuated in the ATZ-treated group, although not significantly compared to the HFD group (Figure 6(c)). The gene expression of insulin receptor in eWAT was not different between the groups (Figure 6(d)). Nevertheless, the TyG index and plasmatic insulin levels were significantly higher in the HFD than in the CT group, and ATZ significantly reduced these parameters (Figures 6(e) and 6(f)). Together, these data suggest that ATZ ameliorates HFD-induced impairment of glucose metabolism.

\section{Discussion}

Long-term oral treatment with ATZ provides strong reduction both in fat deposition and in body weight in HFDinduced obesity mice, accompanied by an improved lipid and glucose metabolism.

We consider two pathways by which ATZ could induce the strong fat loss: in a first line of reasoning, the catalase inhibition and, consequently, the increase in $\mathrm{H}_{2} \mathrm{O}_{2}$ levels, or in a second line of reasoning, the blocking of heme synthesis by inhibiting aminolevulinic acid dehydratase.

The role of catalase in adiposity is still controversial. On the one hand, catalase overexpression in fat inhibits adiposity [29]. On the other hand, knockout animals for catalase show different metabolic profiles according to the literature. The work of Park et al. [9] shows no effect of catalase knockout on body weight and epididymal fat mass either under normal diet or HFD conditions compared to wild type. However, plasma-free fatty acids and triglycerides were increased in catalase knockout animals [9]. Heit et al. [30], in turn, showed that catalase knockout animals presented an increase in body weight and serum triglycerides, despite no difference in WAT weight between wild-type and knockout mice. Our findings identify the opposite after ATZ treatment: the animals decreased all parameters related to HFD-induced obesity, although catalase activity was not completely inhibited in WAT, which supported our second line of reasoning for the mechanism of action for ATZ: heme synthesis inhibition which, in turn, blocks adipogenesis. 


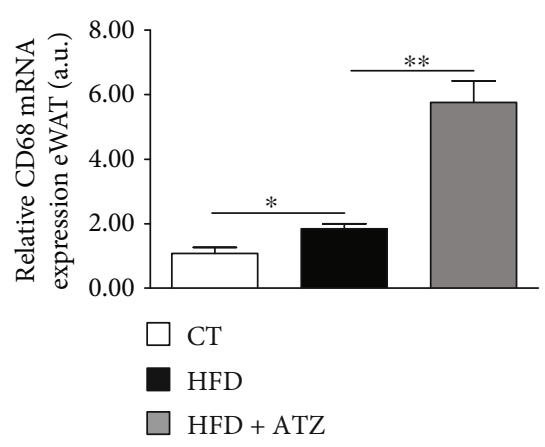

(a)

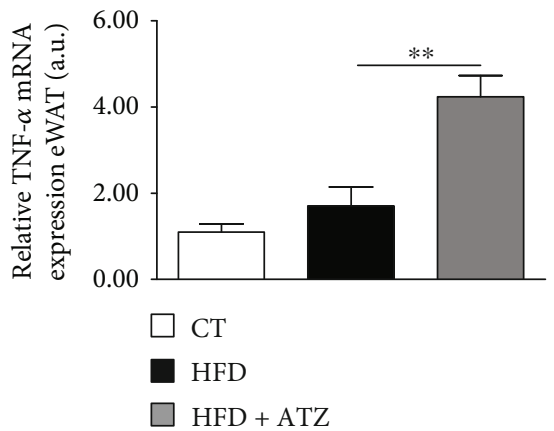

(d)

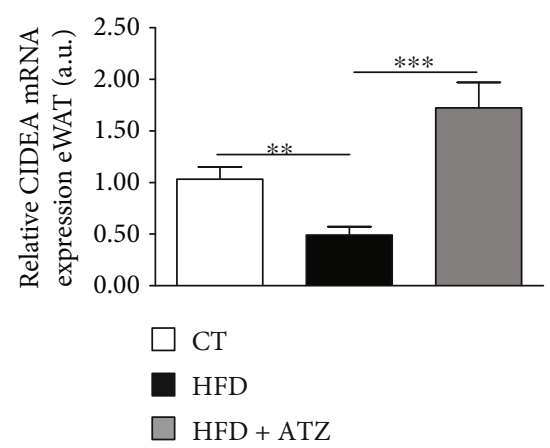

(g)

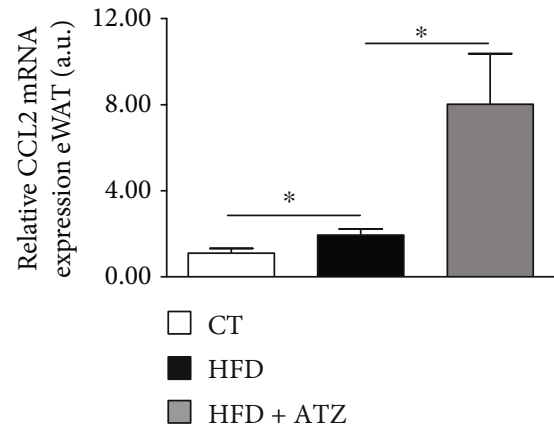

(b)

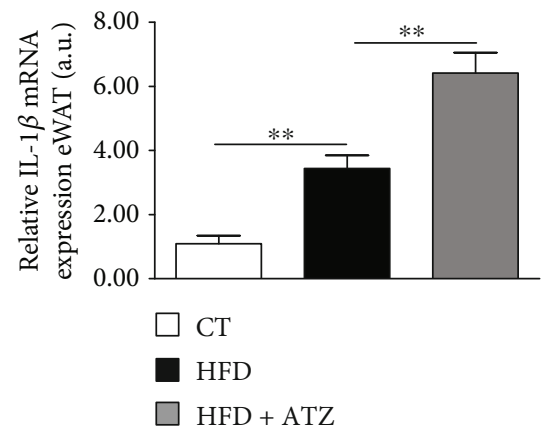

(e)

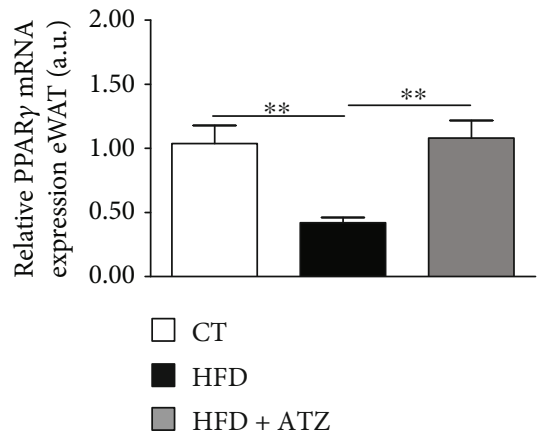

(h)

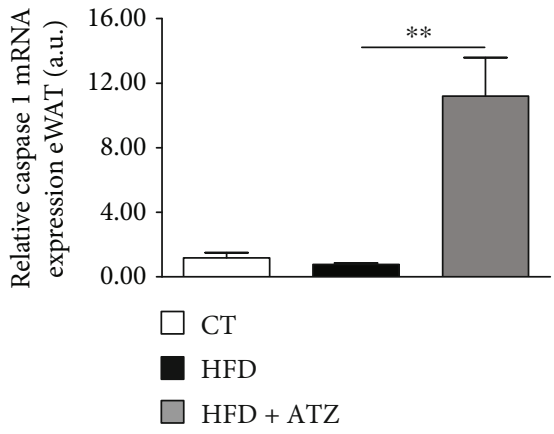

(c)

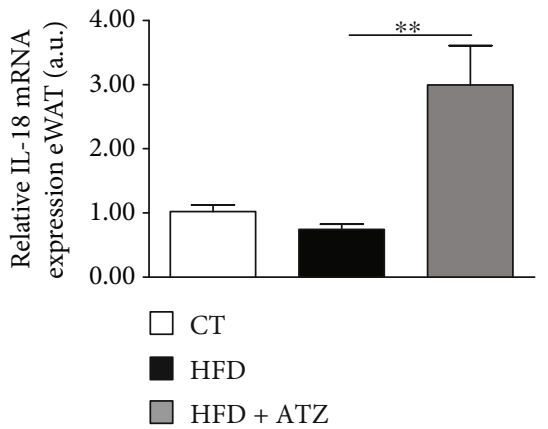

(f)

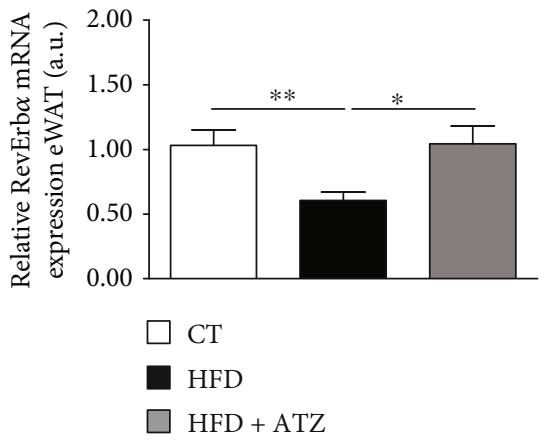

(i)

Figure 4: Relative gene expression of (a) CD68, (b) CCL2, (c) caspase 1, (d) TNF- $\alpha$, (e) interleukin-1 $\beta$, (f) interleukin 18, (g) CIDEA, (h) PPAR $\gamma$, and (i) RevErb $\alpha$ in eWAT (arbitrary units) of C57BL/6 mice after dietetic intervention (chow and high-fat) and oral treatment with ATZ $\left(500 \mathrm{mg} \cdot \mathrm{kg}^{-1}\right)$. Each bar graph represents the mean \pm SEM. ANOVA (one-way): ${ }^{*} p<0.05,{ }^{* *} p<0.01$, and ${ }^{* * *} p<0.001$.

ATZ is an inhibitor of heme biosynthesis [31], which, in turn, leads to blockage of adipogenesis probably by activation of nuclear receptor RevErb $\alpha[14,32]$. Under HFD, this process leads to apoptosis of adipocytes, followed by the invasion of inflammatory cells. The increase in NEFA release, as evidenced by lipolysis in vivo, a marked atrophy in WAT, and the decrease in adipocyte diameter are consequences of blocking adipogenesis, enhanced inflammation, and apoptosis induced by ATZ. Also, most of our gene expression data for inflammatory and cell death markers fit to this scenario: increase in CD68, CCL2, caspase 1 , TNF- $\alpha$, IL-1 $\beta$, IL-18, and CIDEA in WAT. In addition, the WAT of the ATZ group presented a high amount of macrophages. During adipose tissue inflammatory response, such as that occurring in obese WAT, CCL2 binds its receptor CCR2 activating the monocyte transmigration and differentiation into M1 macro- phages. The classical M1 pathway induces the production of proinflammatory cytokines (for example, IL- $1 \beta$, IL-6, and TNF- $\alpha$ ) $[33,34]$, which concur with the scenario observed in WAT of the ATZ-treated group. Corroborating the findings of our data, Park et al. [9], who used knockout mice for catalase, as well as mice that received ATZ as a pharmacological inhibitor of catalase, showed macrophage infiltration into WAT [9].

Functioning as a RevErb $\alpha$ ligand, heme is an important signaling molecule for the induction of adipogenesis [35]. Our hypothesis is that ATZ may interfere with the adipogenic programming probably by activation of nuclear receptor $\operatorname{RevErb} \alpha$, a pivotal player in adipocyte differentiation $[14,35]$. Fontaine et al. [36] identified the gene of $\operatorname{RevErb} \alpha$ as a target for nuclear receptor PPAR $\gamma$ [37-39] in adipogenesis and as a modulator of adipocyte function. 


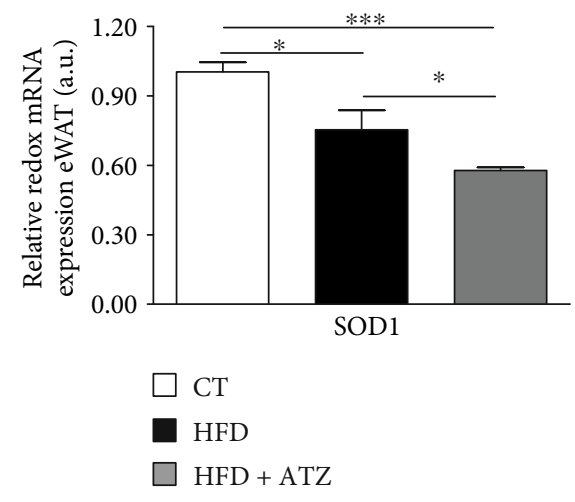

(a)

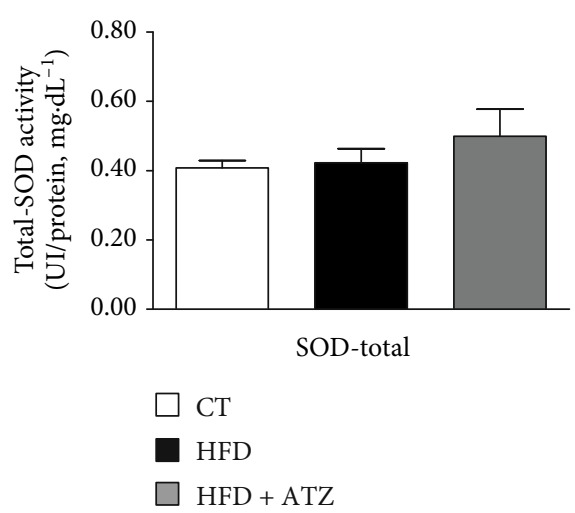

(d)

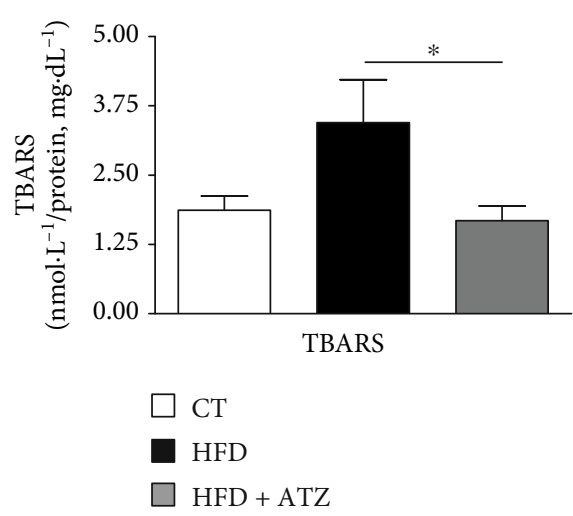

(f)
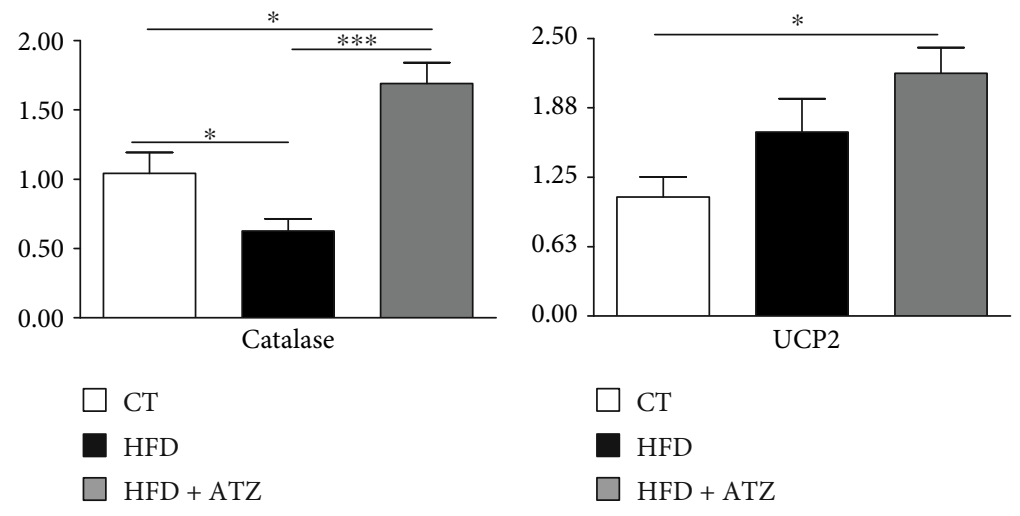

(b)

(c)

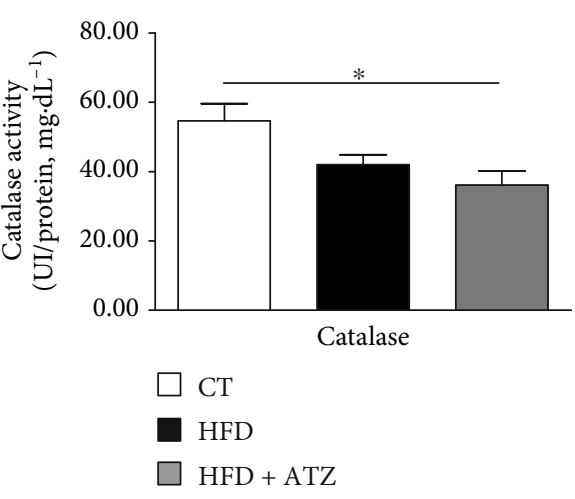

(e)

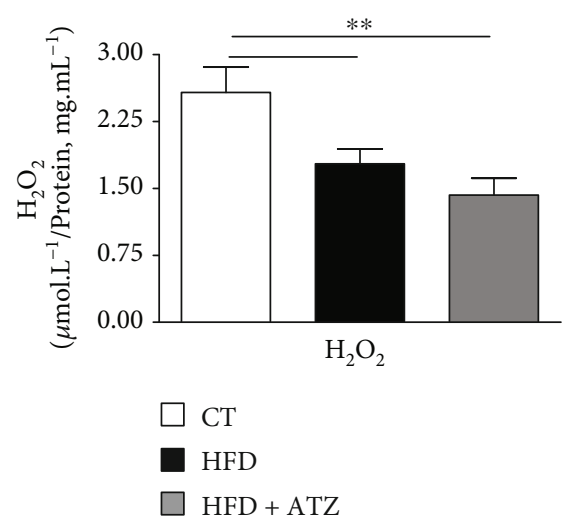

(g)

FIGURE 5: (a-c) Relative gene expression of SOD1, catalase, and UCP2 in WAT (arbitrary units), respectively; (d) SOD activity (UI/protein, $\mathrm{mg} \cdot \mathrm{dL}^{-1}$ ) in eWAT. (e) Catalase activity (UI/protein, mg. $\mathrm{dL}^{-1}$ ) in eWAT; (f) TBARS levels (nmol. $\mathrm{L}^{-1} / \mathrm{protein}, \mathrm{mg}^{-1} \mathrm{dL}^{-1}$ ) in WAT; $\left(\mathrm{g}\right.$ ) $\mathrm{H}_{2} \mathrm{O}_{2}$ levels $\left(\mu \mathrm{mol} \cdot \mathrm{L}^{-1} /\right.$ protein, $\left.\mathrm{mg} \cdot \mathrm{mL}^{-1}\right)$ in eWAT of C57BL/6 mice after dietetic intervention (chow and high-fat) and oral treatment with ATZ $\left(500 \mathrm{mg} \cdot \mathrm{kg}^{-1}\right)$. Each bar graph represents the mean \pm SEM. ANOVA (one-way): ${ }^{*} p<0.05,{ }^{* *} p<0.01$, and ${ }^{* * *} p<0.001$.

PPAR $\gamma$ hypomorphic mice $\left(P P A R \gamma^{\text {hyphyp }}\right)$ presented neonatal mortality; the surviving animals exhibited a lipodystrophy, with moderate glucose intolerance but not a fatty liver, and compensatory regulation of genes in the muscle that allowed the oxidation of lipid excess [40]. On the other hand, adipose-specific PPAR $\gamma$ knockout causes insulin resistance in the fat and liver, and these animals are more susceptible to HFD-induced insulin resistance and steatosis [37]. Together, these studies highlight the relevance of PPAR $\gamma$ in lipid and glycemic metabolism, as well as support the idea that the observed improvement of these pathways in obese animals treated with ATZ may be a reflection of the high level of PPAR $\gamma$ associated with fat loss.

Wang and Lazar [14] identified a bifunctional role of $\operatorname{RevErb} \alpha$ in adipocyte differentiation in vitro. Their work showed that during adipogenesis, the mRNA increases but protein expression behaves differently: during the initial stages of differentiation it increases, because of being required for 


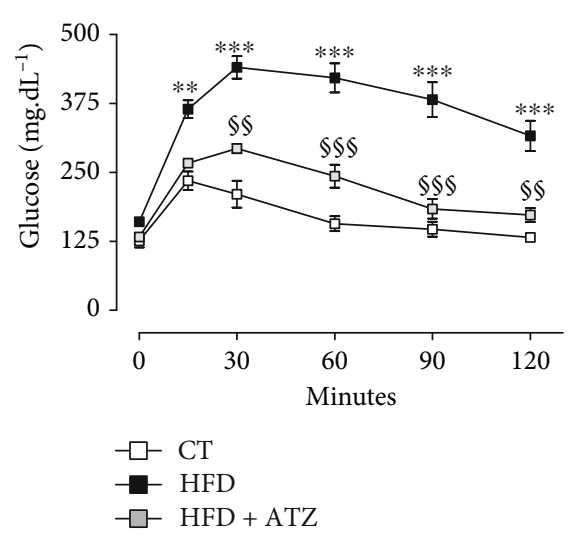

(a)

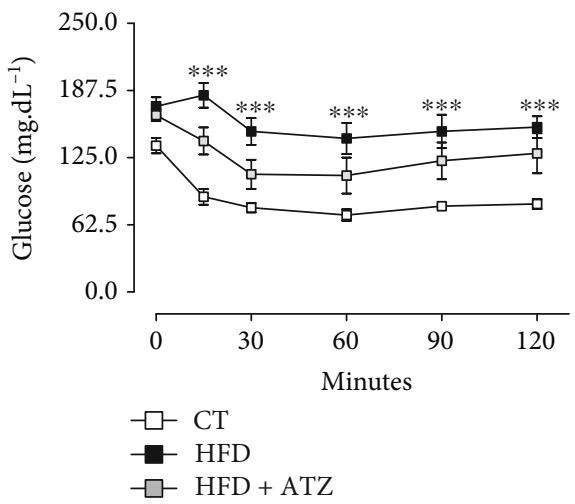

(c)

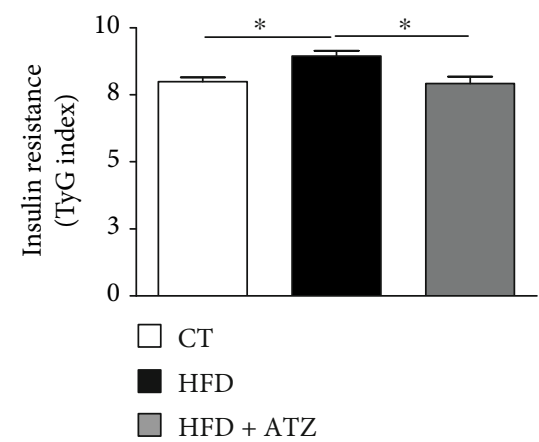

(e)

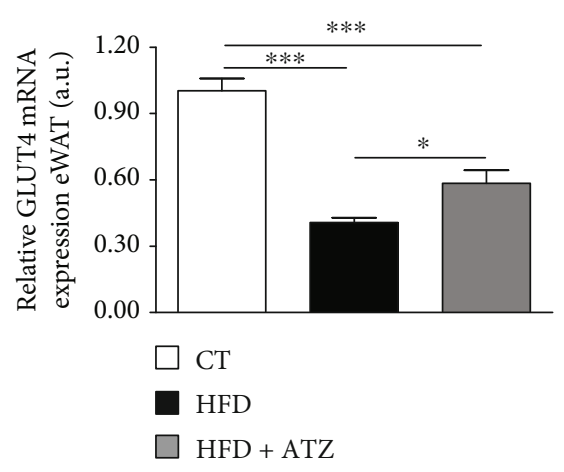

(b)

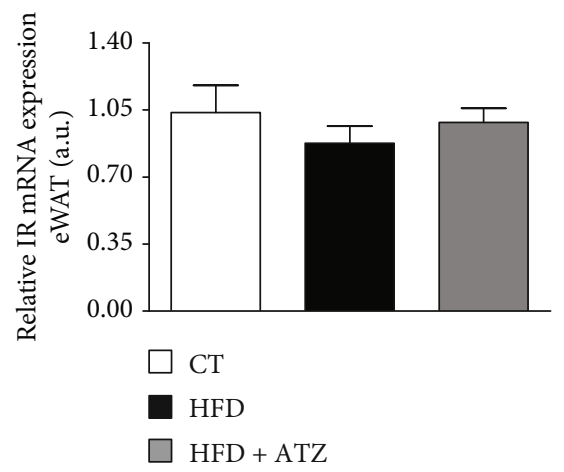

(d)

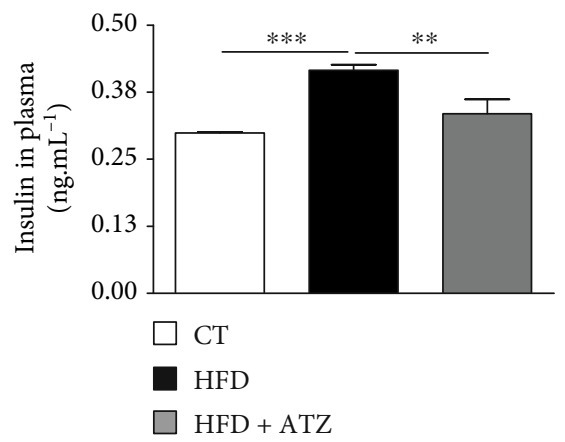

(f)

FIGURE 6: (a) Blood glucose levels in the glucose tolerance test $\left(\mathrm{mg} \cdot \mathrm{dL}^{-1}\right)$; (b) relative gene expression of GLUT4 in eWAT (arbitrary units); (c) blood glucose levels in the insulin tolerance test $\left(\mathrm{mg} \cdot \mathrm{dL}^{-1}\right) ;(\mathrm{d})$ relative gene expression of insulin receptor (IR) in eWAT (arbitrary units); (e) insulin resistance (TyG index); (f) insulin levels in plasma (ng. $\mathrm{mL}^{-1}$ ) of C57BL/6 mice after dietetic intervention (chow and high-fat) and oral treatment with ATZ $\left(500 \mathrm{mg} \cdot \mathrm{kg}^{-1}\right)$. Each point on the graph represents the mean \pm SEM. ANOVA (two-way): ${ }^{* *} p<0.01 ;{ }^{* * *} p<0.001 \mathrm{HFD}$ vs. CT; ${ }^{\circledR \S} p<0.01 ;{ }^{\S s} p<0.001$ HFD+ATZ vs. HFD. Each bar graph represents the mean \pm SEM. ANOVA (one-way): ${ }^{*} p<0.05,{ }^{* *} p<0.01$, and ${ }^{* * *} p<0.001$.

the early mitogenic event during 3T3-L1 cell adipogenesis. Still, at later stages, RevErb $\alpha$ protein levels are decreased, because its degradation is necessary for continued differentiation, since it inhibits the adipogenic programming by repressing the expression of PPAR $\gamma$. According to these data, we would expect an increase in the gene expression of RevErb $\alpha$ and a decrease in PPAR $\gamma$, but both were increased in the ATZ group, suggesting that the augmentation of $\operatorname{PPAR} \gamma$ is compensatory to the drastic loss of fat. Accordingly, data from our group showed that mice treated for 5 days with ATZ exhibited decreased PPAR $\gamma$ mRNA in WAT (data not shown), confirming that $\operatorname{PPAR} \gamma$ expression is indeed suppressed in the beginning of treatment.

As a result of fat loss and probably also the increase in PPAR $\gamma$, previously discussed, the animals treated with ATZ showed improvement in several parameters that were impaired by consumption of HFD: the decrease in leptin plasma levels and gene expression in WAT, regulating energy intake and expenditure [41]; the increase in HSL gene expression, contributing to lipolysis [42]; the increased BAT 


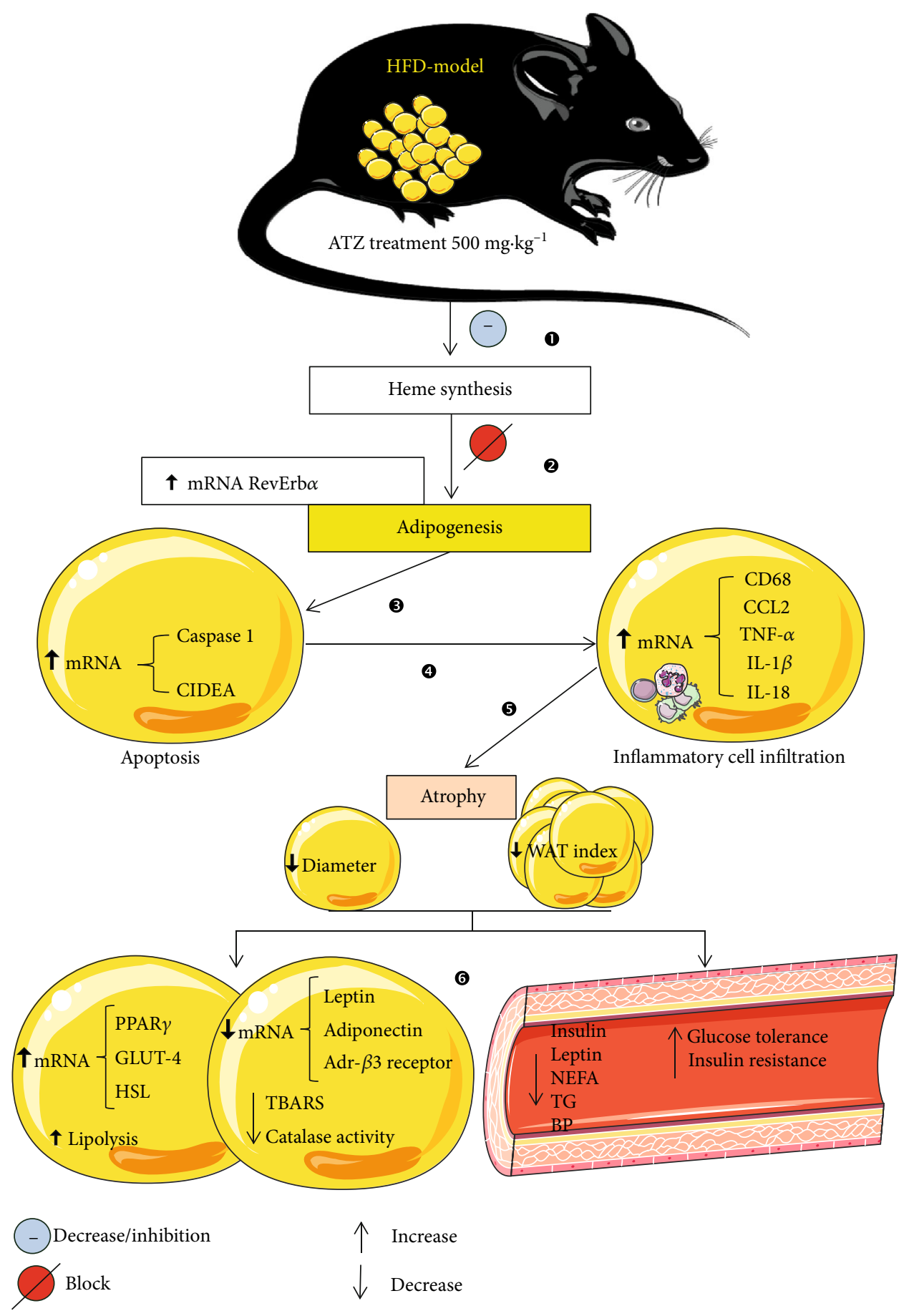

FIgURe 7: Proposed mechanism by which ATZ acts: in the context of HFD-induced obesity and metabolic syndrome in mice (HFD-model), ATZ treatment probably induces heme synthesis inhibition/decrease (1), which blocks adipogenesis by increasing RevErb $\alpha$ gene expression and, possibly, decreasing RevErb $\alpha$ activity (2), leading to apoptosis of adipocytes, evidenced by the increases in mRNA for caspase 1 and cell death activator (CIDEA) (3). This condition promotes inflammatory cell infiltration in epididymal white adipose tissue (eWAT), confirmed by the increased expression of marker genes: cluster of differentiation 68 (CD68), monocyte chemoattractant protein 1 (MCP1 or CCL2), tumor necrosis factor alpha (TNF- $\alpha$ ), interleukin $1 \beta$ (IL-1 $\beta$ ), and interleukin 18 (IL-18) (4), inducing atrophy in eWAT, as well as the decreases in adipocyte diameter and WAT index (5). As a consequence of fat loss, ATZ elicits a beneficial systemic antiobesity effect and improves the metabolic status by increasing lipolysis in vivo, peroxisome proliferator-activated receptor gamma (PPAR $\gamma$ ), glucose transporter 4 (GLUT4), and hormone-sensitive lipase (HSL) genes, as well as by decreasing lipid peroxidation (TBARS), catalase activity, and mRNA for leptin, adiponectin, and beta-3 adrenergic receptor (Adr- $\beta 3$ receptor) in eWAT. In addition, systemically, ATZ decreases insulin, leptin, nonesterified fatty acid (NEFA), triglyceride (TG) levels, and blood pressure, which results in the improvement of glucose tolerance and insulin sensitivity (6). 
amount, which may reflect on thermogenic improvement [43]; the amelioration of insulin and glucose regulation evidenced by the decrease in glucose intolerance, insulin resistance, and insulin plasma levels, as well as the increase in GLUT4 expression in WAT, the main glucose transporter expressed in adipose tissue [44]; and the decrease in plasma lipid levels. Moreover, the ATZ treatment decreased the liver weight, which may reflect the decrease in hepatic lipid deposition $(\mathrm{HFD}=0.0960 \pm 0.01$ vs. $\mathrm{HFD}+\mathrm{ATZ}=0.0695 \pm 0.01$; $p<0.05)$. ATZ decreased the adiponectin mRNA in WAT; we consider two alternatives to explain: in a first line of reasoning, it could be attributed to the drastic decrease in the WAT index, or in a second line of reasoning, the blocking of adipogenesis, which also interferes with the production of anti-inflammatory cytokines such as adiponectin. In addition, the increase in catalase and the decrease in SOD gene expression in WAT could indicate a compensatory mechanism related to the partial inhibition of catalase. Interestingly, chronic ATZ-treatment diminished HFD-induced lipid peroxidation, a marker for oxidative stress [5].

The heme hypothesis is not consistent with all data. It is possible that ATZ performed a mixed action in adipose tissue. Thus, we cannot discard other ATZ effects, such as inhibition of acetyl-CoA carboxylase and thereby fatty acid synthesis in the liver [45], which can contribute to the decrease in lipid depots. Nevertheless, the exact mechanism involved in the ATZ action in body weight and WAT depots, as well as in redox signaling, be it local or systemic, needs more investigations.

Collectively, we show that ATZ induces quick and strong fat loss probably through heme synthesis inhibition which blocks adipogenesis by probably decreasing RevErb $\alpha$ activity. As a consequence, adipocytes become apoptotic, which leads to the recruitment of macrophages and inflammation in WAT. This strong antiobesity effect of ATZ together with the low toxicity of this compound [46], and the beneficial secondary effects on blood pressure, lipid and glucose metabolism, could make it a new treatment option for both obesity and MetS. According to the results of the present work, Figure 7 highlights the proposed mechanism by which ATZ acts.

\section{Summary}

Our findings give new insight into the action of ATZ on lipid metabolism. Considering its low toxicity, ATZ could represent an old compound with novel mechanisms of action to be studied for the treatment of both obesity and metabolic syndrome.

\section{Abbreviations}

$\operatorname{Adr} \beta 3:$

ATZ:

BAT:

BIH:

CD68:

CIDEA:

CT:

Beta-3 adrenergic receptor

3-Amino-1,2,4-triazole

Brown adipose tissue

Berlin Institute of Health

Cluster of differentiation 68

Cell death activator

Control
DZHK:

German Center for Cardiovascular

Research

eWAT: $\quad$ Epididymal white adipose tissue

FANUT: $\quad$ Faculdade de Nutrição

GLUT4: $\quad$ Glucose transporter 4

$\mathrm{H}_{2} \mathrm{O}_{2}$ : Hydrogen peroxide

HFD: High-fat diet

HSL: $\quad$ Hormone-sensitive lipase

ICBS: Instituto de Ciências Biológicas e da

Saúde

IL-1 $\beta$ : $\quad$ Interleukin $1 \beta$

IL-18: $\quad$ Interleukin 18

IR: Insulin receptor

LPL: $\quad$ Lipoprotein lipase

MCP1 or CCL2: $\quad$ Monocyte chemoattractant protein 1

MetS:

Metabolic syndrome

NEFA:

$\operatorname{PPAR} \gamma$ :

Nonesterified fatty acid

Peroxisome proliferator-activated receptor gamma

RevErb $\alpha$ or NR1D1: Nuclear receptor subfamily 1

SOD: $\quad$ Superoxide dismutase

TBARS: $\quad$ Thiobarbituric acid reactive substances

TCOL: Total cholesterol

TG: Triglycerides

TNF- $\alpha$ : Tumor necrosis factor alpha

TyG index: $\quad$ Triglyceride and glucose levels index

UCP2: Uncoupling protein

UFAL: Universidade Federal de Alagoas

UFPE: $\quad$ Universidade Federal de Pernambuco

WAT: White adipose tissue.

\section{Data Availability}

The data used to support the findings of this study are available from the corresponding author upon request.

\section{Additional Points}

Highlights. 3-Amino-1,2,4-triazole (ATZ) is a potent antiobesity agent in HFD-induced metabolic syndrome mice. ATZ is a potent inducer of white fat loss and body weight reduction. ATZ may act through heme synthesis inhibition, which blocks adipogenesis by the increase in mRNA RevErb $\alpha$. Under HFD, this ATZ action leads to apoptosis of adipocytes and the invasion of inflammatory cells. The drastic and rapid decrease in white adipose tissue induced by ATZ improved metabolic parameters.

\section{Conflicts of Interest}

The authors declare that there is no conflict of interests regarding the publication of this paper.

\section{Authors' Contributions}

VNS, MB, and LAR conceived and designed the experiments. VNS, NMDJ, MAES, VPFN, FAM, and LAR performed the experiments. VNS, NMDJ, FAM, and LAR analyzed the data. VNS, NMDJ, MAES, MB, and LAR interpreted the results of 
experiments. NA, MB, and LAR contributed with reagents/materials/animals/analysis tools. VNS, NMDJ, MAES, and LAR wrote the paper. VNS, NMDJ, FAM, and LAR prepared figures. NA, MB, and LAR edited and revised the manuscript.

\section{Acknowledgments}

We would like to acknowledge the assistance of Glaucevane da Silva Guedes in animal care. The authors wish to thank Coordenação de Aperfeiçoamento de Pessoal de Nível Superior (CAPES; Grant PROCAD-NF 2450) and Conselho Nacional de Desenvolvimento Científico e Tecnológico (CNPq; 483049/2009-3), for the financial support. NMDJ was supported by the Fellowship CAPES-Brazil. VPNF received a PIBIC-Fellowship from CNPq-Brazil.

\section{References}

[1] K. G. Alberti, R. H. Eckel, S. M. Grundy et al., "Harmonizing the metabolic syndrome: a joint interim statement of the International Diabetes Federation Task Force on Epidemiology and Prevention; National Heart, Lung, and Blood Institute; American Heart Association; World Heart Federation; International Atherosclerosis Society; and International Association for the Study of Obesity," Circulation, vol. 120, no. 16, pp. 16401645, 2009.

[2] C. Day, "Metabolic syndrome, or what you will: definitions and epidemiology," Diabetes \& Vascular Disease Research, vol. 4, no. 1, pp. 32-38, 2007.

[3] N. Kloting and M. Bluher, "Adipocyte dysfunction, inflammation and metabolic syndrome," Reviews in Endocrine \& Metabolic Disorders, vol. 15, no. 4, pp. 277-287, 2014.

[4] L. Luo and M. Liu, "Adipose tissue in control of metabolism," The Journal of Endocrinology, vol. 231, no. 3, pp. R77-R99, 2016.

[5] H. Otani, "Oxidative stress as pathogenesis of cardiovascular risk associated with metabolic syndrome," Antioxidants \& Redox Signaling, vol. 15, no. 7, pp. 1911-1926, 2011.

[6] E. Margoliash and A. Novogrodsky, "A study of the inhibition of catalase by 3-amino-1:2:4:-triazole," The Biochemical Journal, vol. 68, no. 3, pp. 468-475, 1958.

[7] M. Casteels, K. Croes, P. P. Van Veldhoven, and G. P. Mannaerts, "Aminotriazole is a potent inhibitor of alphaoxidation of 3-methyl-substituted fatty acids in rat liver," Biochemical Pharmacology, vol. 48, no. 10, pp. 1973-1975, 1994.

[8] F. J. Ruiz-Ojeda, C. Gomez-Llorente, C. M. Aguilera, A. Gil, and A. I. Ruperez, "Impact of 3-amino-1,2,4-triazole (3-AT)derived increase in hydrogen peroxide levels on inflammation and metabolism in human differentiated adipocytes," PLoS One, vol. 11, no. 3, article e0152550, 2016.

[9] Y. S. Park, M. J. Uddin, L. Piao, I. Hwang, J. H. Lee, and H. Ha, "Novel role of endogenous catalase in macrophage polarization in adipose tissue," Mediators of Inflammation, vol. 2016, Article ID 8675905, 14 pages, 2016.

[10] W. J. Hayes, Pesticides studies in man, The Williams \& Wilkins Co, Baltimore, 1982.

[11] T. B. Gaines, R. D. Kimbrough, and R. E. Linder, "The toxicity of amitrole in the rat," Toxicology and Applied Pharmacology, vol. 26, no. 1, pp. 118-129, 1973.

[12] International Agency for Research on Cancer, "IARC Monographs programme on the evaluation of the carcinogenic risk of chemicals to humans," in Vol. 25. Wood, leather and some associated industries, WHO, Geneva, Switzerland, 1981.

[13] D. Steinhoff, H. Weber, U. Mohr, and K. Boehme, "Evaluation of amitrole (aminotriazole) for potential carcinogenicity in orally dosed rats, mice, and golden hamsters," Toxicology and Applied Pharmacology, vol. 69, no. 2, pp. 161-169, 1983.

[14] J. Wang and M. A. Lazar, "Bifunctional role of Rev-erbalpha in adipocyte differentiation," Molecular and Cellular Biology, vol. 28, no. 7, pp. 2213-2220, 2008.

[15] G. L. Jones and A. R. Neill, "The effects of clofibrate and 3-amino-1,2,4-triazole on liver catalase and lipid metabolism in mice," Biochimica et Biophysica Acta, vol. 712, no. 2, pp. 420-426, 1982.

[16] V. Nunes-Souza, C. J. César-Gomes, L. J. S. Da Fonseca, G. D. S. Guedes, S. Smaniotto, and L. A. Rabelo, "Aging increases susceptibility to high fat diet-induced metabolic syndrome in C57BL/6 mice: improvement in glycemic and lipid profile after antioxidant therapy," Oxidative Medicine and Cellular Longevity, vol. 2016, Article ID 1987960, 17 pages, 2016.

[17] L. E. Simental-Mendia, M. Rodriguez-Moran, and F. Guerrero-Romero, "The product of fasting glucose and triglycerides as surrogate for identifying insulin resistance in apparently healthy subjects," Metabolic Syndrome and Related Disorders, vol. 6, no. 4, pp. 299-304, 2008.

[18] F. Guerrero-Romero, L. E. Simental-Mendía, M. GonzálezOrtiz et al., "The product of triglycerides and glucose, a simple measure of insulin sensitivity. Comparison with the euglycemic-hyperinsulinemic clamp," The Journal of Clinical Endocrinology \& Metabolism, vol. 95, no. 7, pp. 3347-3351, 2010.

[19] L. Qiao, B. Kinney, J. Schaack, and J. Shao, "Adiponectin inhibits lipolysis in mouse adipocytes," Diabetes, vol. 60, no. 5, pp. 1519-1527, 2011.

[20] L. Fu, K. Isobe, Q. Zeng, K. Suzukawa, K. Takekoshi, and Y. Kawakami, "The effects of beta(3)-adrenoceptor agonist CL-316,243 on adiponectin, adiponectin receptors and tumor necrosis factor-alpha expressions in adipose tissues of obese diabetic KKAy mice," European Journal of Pharmacology, vol. 584, no. 1, pp. 202-206, 2008.

[21] M. M. Bradford, "A rapid and sensitive method for the quantitation of microgram quantities of protein utilizing the principle of protein-dye binding," Analytical Biochemistry, vol. 72, pp. 248-254, 1976

[22] P. Xu, A. C. Costa-Goncalves, M. Todiras et al., "Endothelial dysfunction and elevated blood pressure in MAS genedeleted mice," Hypertension, vol. 51, no. 2, pp. 574-580, 2008.

[23] H. Ohkawa, N. Ohishi, and K. Yagi, "Assay for lipid peroxides in animal tissues by thiobarbituric acid reaction," Analytical Biochemistry, vol. 95, no. 2, pp. 351-358, 1979.

[24] L. J. S. da Fonseca, V. Nunes-Souza, G. da Silva Guedes, G. Schettino-Silva, M. A. Mota-Gomes, and L. A. Rabelo, "Oxidative status imbalance in patients with metabolic syndrome: role of the myeloperoxidase/hydrogen peroxide axis," Oxidative Medicine and Cellular Longevity, vol. 2014, Article ID 898501, 14 pages, 2014.

[25] K. J. Livak and T. D. Schmittgen, "Analysis of relative gene expression data using real-time quantitative PCR and the $2_{-}{ }_{T}^{\Delta \Delta C}$ method," Methods, vol. 25, no. 4, pp. 402-408, 2001.

[26] R. Mendez, Z. Zheng, Z. Fan, S. Rajagopalan, Q. Sun, and K. Zhang, "Exposure to fine airborne particulate matter induces macrophage infiltration, unfolded protein response, 
and lipid deposition in white adipose tissue," American Journal of Translational Research, vol. 5, no. 2, pp. 224-234, 2013.

[27] W. M. T. Kuwabara, A. C. Panveloski-Costa, C. N. F. Yokota et al., "Comparison of Goto-Kakizaki rats and high fat dietinduced obese rats: are they reliable models to study type 2 diabetes mellitus?," PLoS One, vol. 12, no. 12, article e0189622, 2017.

[28] B. P. Sampey, A. M. Vanhoose, H. M. Winfield et al., "Cafeteria diet is a robust model of human metabolic syndrome with liver and adipose inflammation: comparison to high-fat diet," Obesity, vol. 19, no. 6, pp. 1109-1117, 2011.

[29] D. L. Amos, T. Robinson, M. B. Massie et al., "Catalase overexpression modulates metabolic parameters in a new 'stressless' leptin-deficient mouse model," Biochimica et Biophysica Acta (BBA) - Molecular Basis of Disease, vol. 1863, no. 9, pp. 2293-2306, 2017.

[30] C. Heit, S. Marshall, S. Singh et al., "Catalase deletion promotes prediabetic phenotype in mice," Free Radical Biology \& Medicine, vol. 103, pp. 48-56, 2017.

[31] J. J. Chen and I. M. London, "Hemin enhances the differentiation of mouse 3T3 cells to adipocytes," Cell, vol. 26, no. 1, pp. 117-122, 1981.

[32] J. M. Moreno-Navarrete, A. Rodríguez, F. Ortega et al., "Heme biosynthetic pathway is functionally linked to adipogenesis via mitochondrial respiratory activity," Obesity, vol. 25, no. 10, pp. 1723-1733, 2017.

[33] J. Yang, L. Zhang, C. Yu, X. F. Yang, and H. Wang, "Monocyte and macrophage differentiation: circulation inflammatory monocyte as biomarker for inflammatory diseases," Biomarker Research, vol. 2, no. 1, p. 1, 2014.

[34] A. Alisi, G. Carpino, F. L. Oliveira, N. Panera, V. Nobili, and E. Gaudio, "The role of tissue macrophage-mediated inflammation on NAFLD pathogenesis and its clinical implications," Mediators of Inflammation, vol. 2017, Article ID 8162421, 15 pages, 2017.

[35] N. Kumar, L. A. Solt, Y. Wang et al., "Regulation of adipogenesis by natural and synthetic REV-ERB ligands," Endocrinology, vol. 151, no. 7, pp. 3015-3025, 2010.

[36] C. Fontaine, G. Dubois, Y. Duguay et al., "The orphan nuclear receptor Rev-Erbalpha is a peroxisome proliferatoractivated receptor (PPAR) gamma target gene and promotes PPARgamma-induced adipocyte differentiation," The Journal of Biological Chemistry, vol. 278, no. 39, pp. 37672-37680, 2003.

[37] W. He, Y. Barak, A. Hevener et al., "Adipose-specific peroxisome proliferator-activated receptor gamma knockout causes insulin resistance in fat and liver but not in muscle," Proceedings of the National Academy of Sciences, vol. 100, no. 26, pp. 15712-15717, 2003.

[38] P. Tontonoz, E. Hu, and B. M. Spiegelman, "Stimulation of adipogenesis in fibroblasts by PPAR $\gamma 2$, a lipid-activated transcription factor," Cell, vol. 79, no. 7, pp. 1147-1156, 1994.

[39] E. Mueller, "Understanding the variegation of fat: novel regulators of adipocyte differentiation and fat tissue biology," Biochimica et Biophysica Acta (BBA) - Molecular Basis of Disease, vol. 1842, no. 3, pp. 352-357, 2014.

[40] H. Koutnikova, T. A. Cock, M. Watanabe et al., "Compensation by the muscle limits the metabolic consequences of lipodystrophy in PPAR hypomorphic mice," Proceedings of the National Academy of Sciences, vol. 100, no. 24, pp. 1445714462, 2003.
[41] M. F. Andreoli, J. Donato, I. Cakir, and M. Perello, "Leptin resensitisation: a reversion of leptin-resistant states," The Journal of Endocrinology, vol. 241, no. 3, pp. R81-R96, 2019.

[42] A. D. Quiroga and R. Lehner, "Pharmacological intervention of liver triacylglycerol lipolysis: the good, the bad and the ugly," Biochemical Pharmacology, vol. 155, pp. 233-241, 2018.

[43] J. Nedergaard and B. Cannon, "The changed metabolic world with human brown adipose tissue: therapeutic visions," Cell Metabolism, vol. 11, no. 4, pp. 268-272, 2010.

[44] Y. Minokoshi, C. R. Kahn, and B. B. Kahn, "Tissue-specific ablation of the GLUT4 glucose transporter or the insulin receptor challenges assumptions about insulin action and glucose homeostasis," The Journal of Biological Chemistry, vol. 278, no. 36, pp. 33609-33612, 2003.

[45] H. Ishii, Y. Nakagawa, T. Suga, and S. Niinobe, "Inhibition by 3-amino-1,2,4-triazole of fatty acid synthesis in cell free system," Chemical \& Pharmaceutical Bulletin, vol. 26, no. 9, pp. 2674-2678, 1978.

[46] B. Se, "Encyclopedia of chemicals, drugs and biologicals," in The Merck Index -, B. Se, Ed., Merck and Co., Rahway, NJ, 1989. 